\title{
DESAIN ULANG IMPELER POMPA SENTRIFUGAL KURVA PRESTASI SERTA FENOMENA ALIRAN DENGAN CAD-CFD
}

\author{
Fatkur Rachmanu \\ Program Studi Teknik Mesin \\ Politeknik Enjinering Indorama \\ Email: fatkur.rachman@gmail.com
}

\begin{abstract}
ABSTRAK
Pompa adalah alat untuk memindahkan cairan dari dataran rendah ke dataran tinggi. Pengoperasiannya bila lama digunakan akan mengurangi efisiensi dari prestasi pompa tersebut sehingga diperlukan perbaikan dan perawatan. Salah satu perawatannya antara lain dengan memperbaiki komponen utamanya yaitu impeler atau baling-baling. Pada pembuatan impeler tahap pertama adalah desain bentuk impeler dengan memperhatikan beberapa parameter sehingga meningkatan efisiensi pompa. Tujuan penelitian ini adalah untuk mengubah profil impeler agar efisiensi meningkat dan mendapatkan impeler yang lebih efektif dengan bantuan perangkat lunak CAD dan CFD. CFD adalah metode penghitungan, memprediksi, dan pendekatan aliran fluida secara numerik dengan bantuan komputer. CAD mengubah dari model umum menjadi model berdimensi, lalu pendiskritan model dalam CFD sebagai pendekatan dari aliran fluida air yang terjadi pada impeler. Hasil optimalisasi dengan perangkat lunak efisiensi total kinerja pompa meningkat dari $59 \%$ menjadi $61 \%$. Sudut masuk fluida pada sudut masuk sudu impeler $(\beta 1)$ dan sudut keluar sudu impeler $(\beta 2)$ diusahakan diatas $10^{\circ}$, disamping nilai NPSHR menentukan pelayanan kondisi kerja pompa dalam kewajaran. Sudut incident (i) dapat mengubah kinerja pompa. Sesuai hukum pompa sentrifugal yaitu kecepatan isap spesifik (Nss) yang meningkat akan menurunkan tinggi kenaikan isap positif bersih yang diperlukan (NPSHR). Sehingga didapat model impeler yang lebih optimal.
\end{abstract}

Kata kunci: desain, impeler, pompa, sentrifugal, CAD, CFD.

\begin{abstract}
Pumps is a tool to move the liquid from the lowlands to the highlands. Operation when long use will reduce the efficiency of the achievements of the pump so that the necessary repairs and maintenance. One treatment, among others by improving its main components, namely the impeller or propeller. In the manufacture of the first stage impeller is a propeller shape design with respect to some parameters that improve the efficiency of the pump. The purpose of this study was to change the profile impellers in order to maintain the impeller efficiency is increased and more effective with the help of CAD and CFD software. CFD is the method of calculation, to predict, and fluid flow approaches numerically with the aid of a computer. CAD change of the general model becomes a model dimension, then discrete models in CFD. Then as an approximation of the fluid flow of water that occurs on the impeller. Software optimization results with total efficiency of the pump's performance increased from $59 \%$ to $61 \%$. Incoming angles of fluid at an angle of entry of the blade impeller $(\beta 1)$ and corner exit blade impeller $(\beta 2)$ arranged above $10^{\circ}$, in addition to determining the value NPSHR service pump working conditions in fairness. Incident angle ( $i$ ) can alter the performance of the pump. Appropriate law suction centrifugal pump that is speed-specific (Nss) which increases high-rise will reduce the required net positive suction (NPSHR). In order to get a more optimal impeller models.
\end{abstract}

Keywords: design, impeller, pump, centrifugal, CAD, CFD.

\section{PENDAHULUAN}

\subsection{Latar Belakang Penelitian}

Perbaikan (maintenance) suatu mesin-mesin produksi sangatlah dibutuhkan di Indonesia terutama mesin pembangkit dan mesin-mesin pendukung. Adapun waktu, metode, alat, tempat pengerjaan adalah menjadi faktor penentu keberhasilan perbaikan itu sendiri. Jurnal ini membahas penggunaan metode CFD (Computational Fluid Dynamic) untuk desain impeler/baling-baling pompa dan mengacu materi CAD$C A M$. Desain impeler pompa menurut rumus-rumus, metode, desain dengan bantuan buku literatur. 
Kemudian divisualisasikan dengan bantuan CAD (computer Aided Design/Drafting), untuk mengetahui permodelan Impeler. Kapasitas, kecepatan dan tekanan fluida dibantu dengan CAE (Computer Aided Engineering) dalam hal ini CFD. Sesuai persamaan berikut [1][2]:

$$
\frac{\partial(\rho u)}{\partial x}+\frac{\partial(\rho v)}{\partial y}+\frac{\partial(\rho w)}{\partial z}=0
$$

Dan sesuai diagram alur dalam tahapan $C F D$

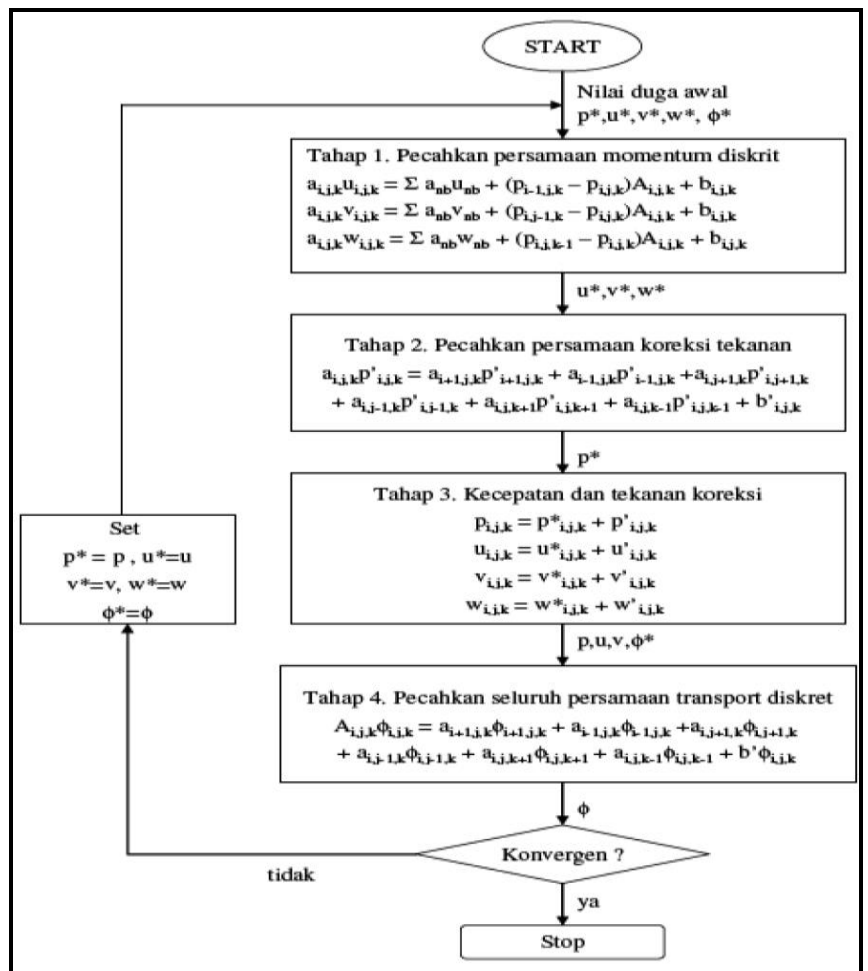

Gambar 1. Diagram Alur Persamaan Matematis Dalam Konsep CFD [3]

Permasalahan pada saat pembongkaran pompa sentrifugal ditemukan impeler mengalami kerusakan permanen karena erosi kavitasi. Proses desain dan pembuatan Impeler pompa dalam hal ini pompa proses, ditambah bila ingin meningkatkan kinerja pompa lebih tinggi ataupun mendekati sama dengan impeler baru.

Batasan penelitian melibatkan tahapan disain sebuah pompa sentrifugal. Sedangkan yang akan dibahas dalam tesis adalah tahapan disain saja hingga permodelan, kurva prestasi dan fenomena aliran fluida tanpa memperhitungkan material, gaya-gaya yang bekerja, momen, dan sebagainya, yang disebabkan oleh reaksi perlawanan fluida yang sangat kompleks akibat putaran poros pompa dari sebuah impeler pompa sentrifugal. Harga dan waktu untuk manufaktur impeler pompa.

Fluida yang digunakan adalah air tanah dengan kondisi normal dan dianggap bersih tidak mengandung benda padat atau pasir. Mendisain ulang dengan hanya memperhatikan bentuk impeler dengan bantuan software. Serta simulasi aliran dengan $C A D-C F D$ : Perpindahan panas didalam rumah pompa diabaikan, Penelitian dilakukan pada pompa Gould pump tipe 3900L vertical inline API 610 edisi ke $9 \mathrm{OH} 4$ [4].

\section{METODOLOGI PENELITIAN}

Adapun diagram alur penelitian adalah sebagai berikut: 


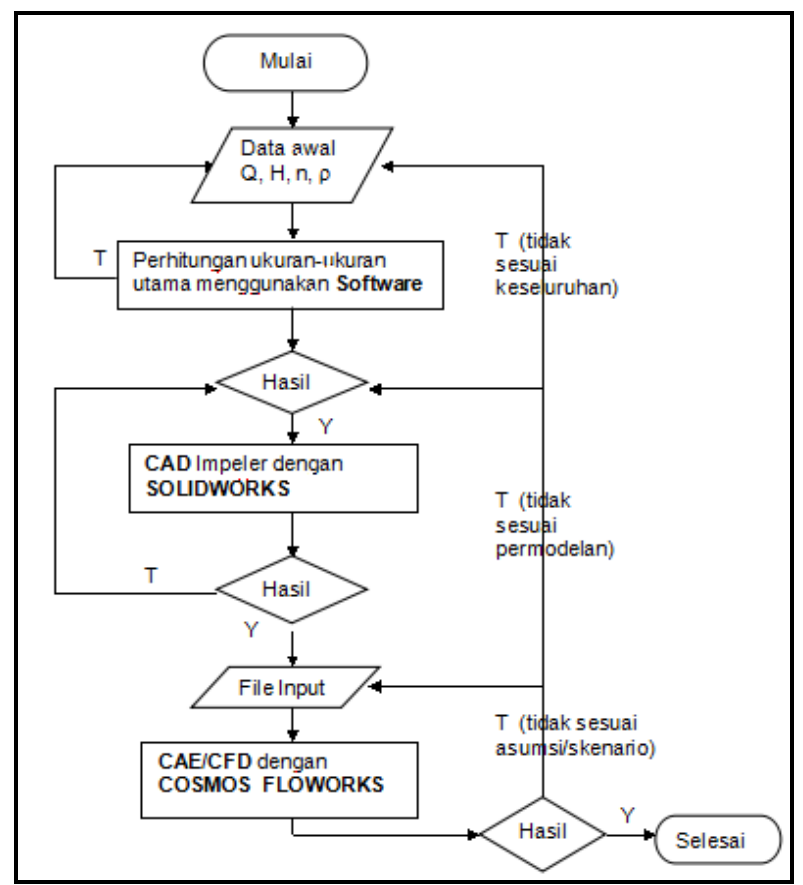

Gambar 2. Diagram Alur Prosedur Penelitian

\section{HASIL PENELITIAN}

Analisa dan perhitungannya adalah sebagai berikut: Data Input Debit $(\mathrm{Q})=300 \mathrm{GPM}=68,13 \mathrm{~m}^{3} / \mathrm{h}$ $=0.018925 \mathrm{~m}^{3} /$ det, pada ketinggian $/$ head $(H)=170,94 \mathrm{ft}=52,1 \mathrm{~m}$, Putaran pompa $\left(n_{p}\right)=1478 \mathrm{rpm}[5]$.

\subsection{Perhitungan Simulasi}

Kurva prestasi pompa yang dihasilkan oleh perangkat lunak adalah sebagai berikut:

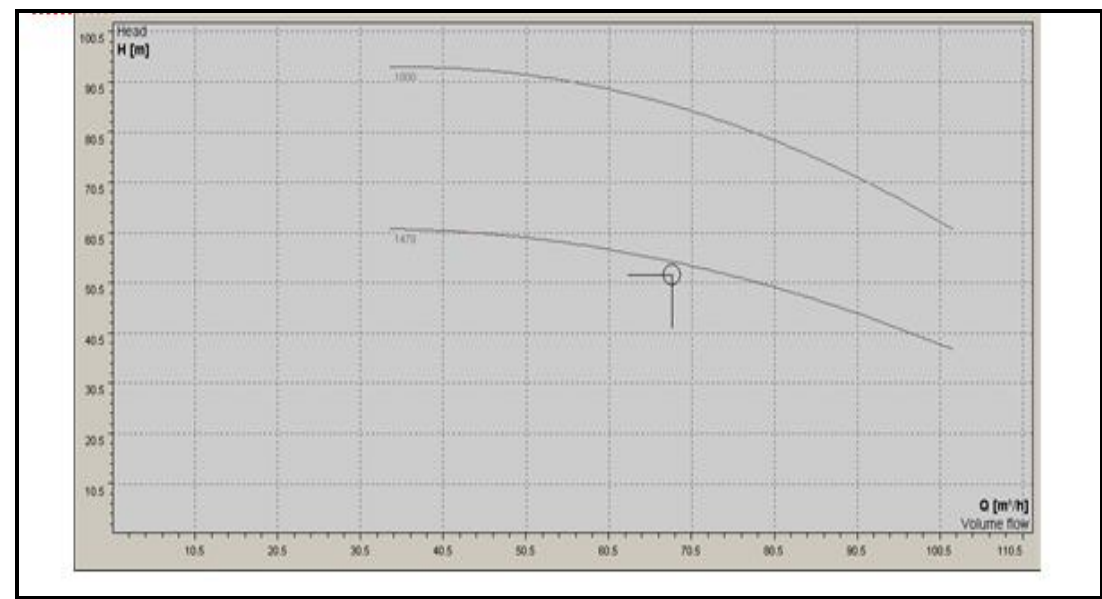

Gambar 3. Perhitungan Dengan Software Sebelum Optimasi (pada q= 68.13 m3/jam Dan h = 52.1m, n = 1478 rpm, Frekuensi Motor Listrik 50hz) 
Sedangkan kurva prestasi hasil pengujian lapangan sebelum optimasi adalah:

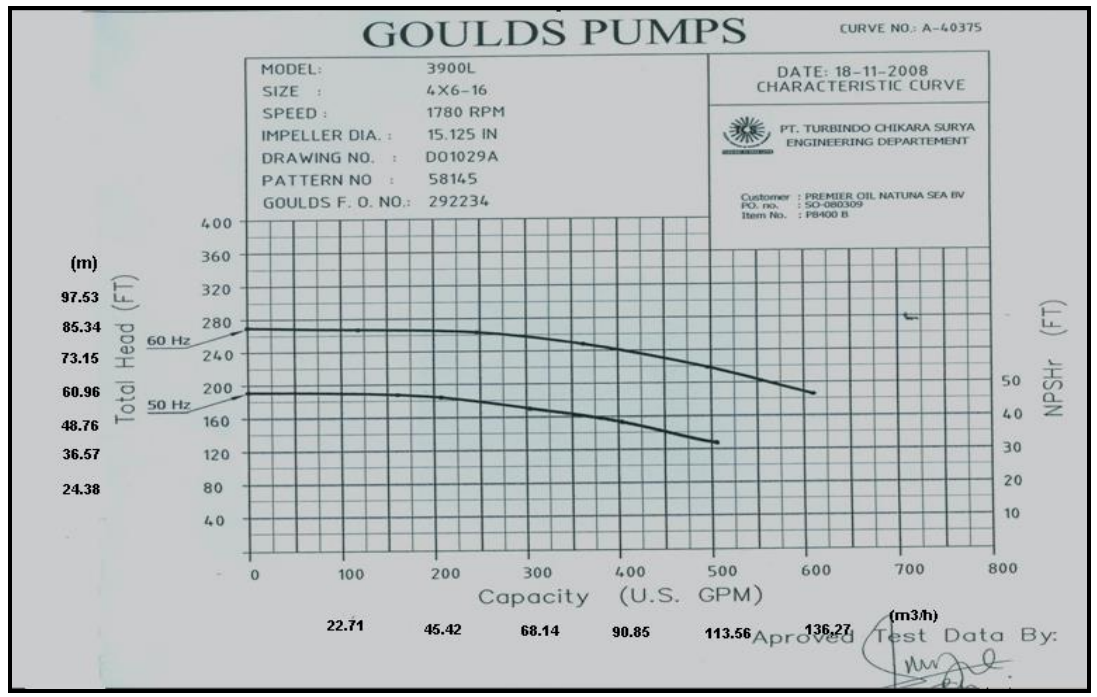

Gambar 4. Prestasi Pompa Hasil Pengukuran [6]

Terlihat hasil perhitungan dengan menggunakan software akan mendekati sama dengan pengujian di lapangan uji. Adapun perbedaan karena rugi-rugi (loss) pada pengujian sesungguhnya / lapangan, baik itu adanya kebocoran, rugi-rugi belokan pipa, katup, ketidakakuratan alat uji ataupun rugi aliran balik impeler keluar dari impeler masuk kembali ke sisi isap / recirculation impeler wear ring/casing ring. Setelah perhitungan untuk pompa sentrifugal maka digambarkan dengan menggunakan $C A D$ SOLIDWORKS 2010, yang menghasilkan gambar 5 sebagai berikut:

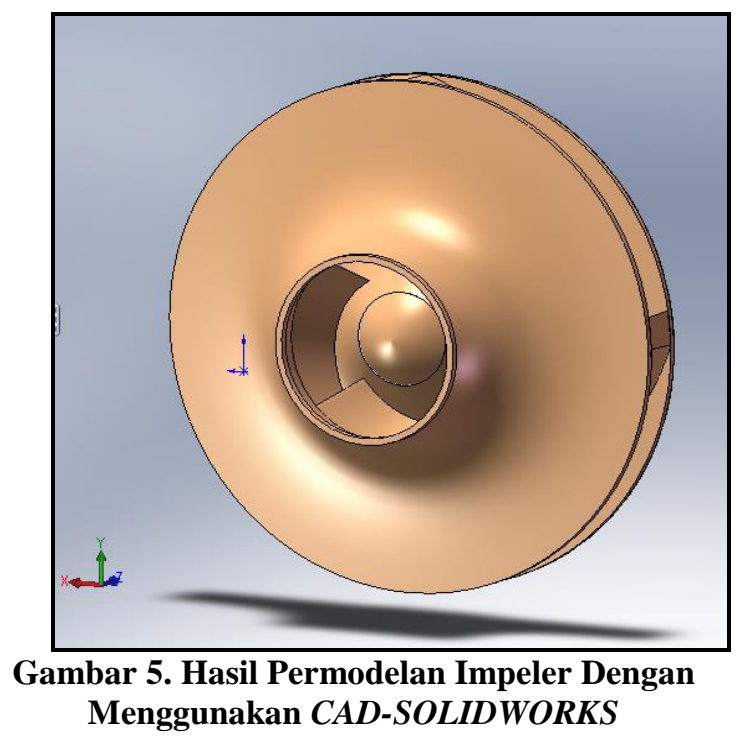

\subsection{Distribusi Kecepatan Meridional}

Kecepatan fluida sebelum masuk impeler tinggi kemudian menurun bervariasi pada daerah sudu LE/leading edge kemudian menyatu sebelum TE/trailing edge kemudian meningkat drastis keluar dari impeler dibantu dengan rumah/volute pompa sehingga kecepatan yang lebih tinggi dibandingkan sisi masuk impeler. Kemudian dioptimasi sehingga menghasilkan luaran seperti pada gambar 6 berikut: 


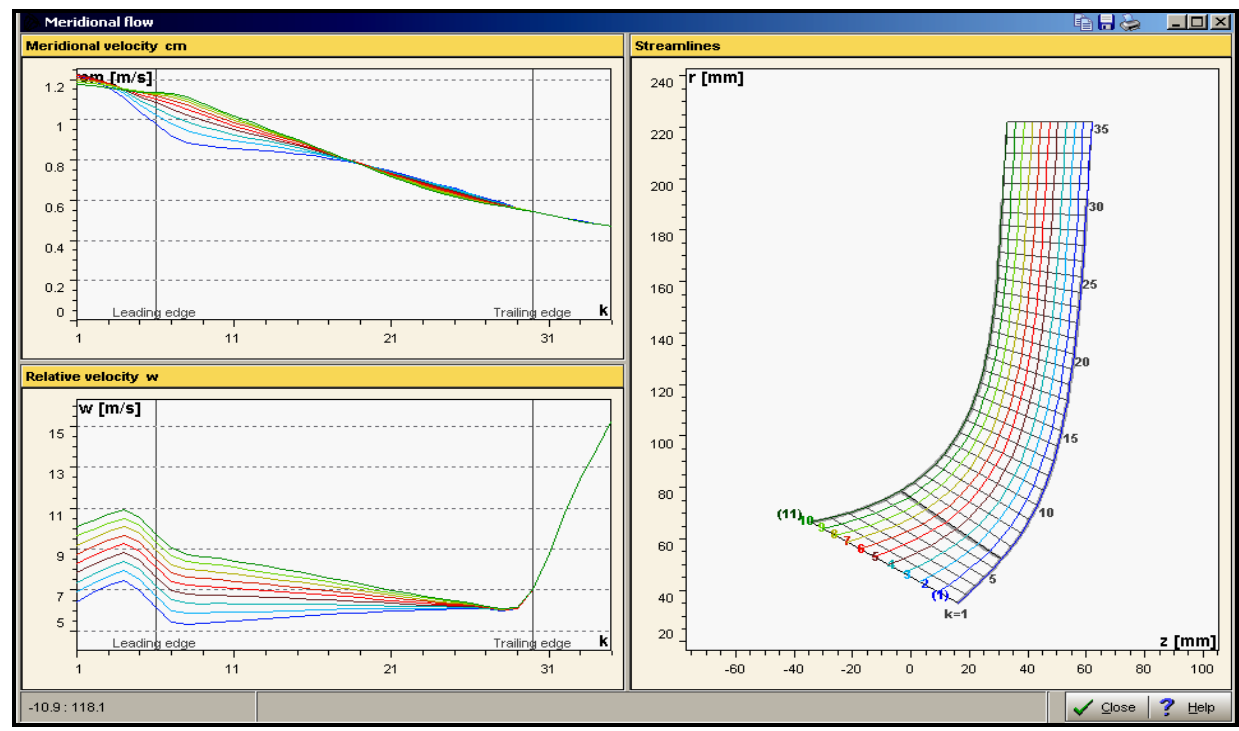

Gambar 6. Distribusi Kecepatan Meridional Menggunakan Software

Keterangan: warna hijau tua daerah leading edge, biru tua daerah trailing edge

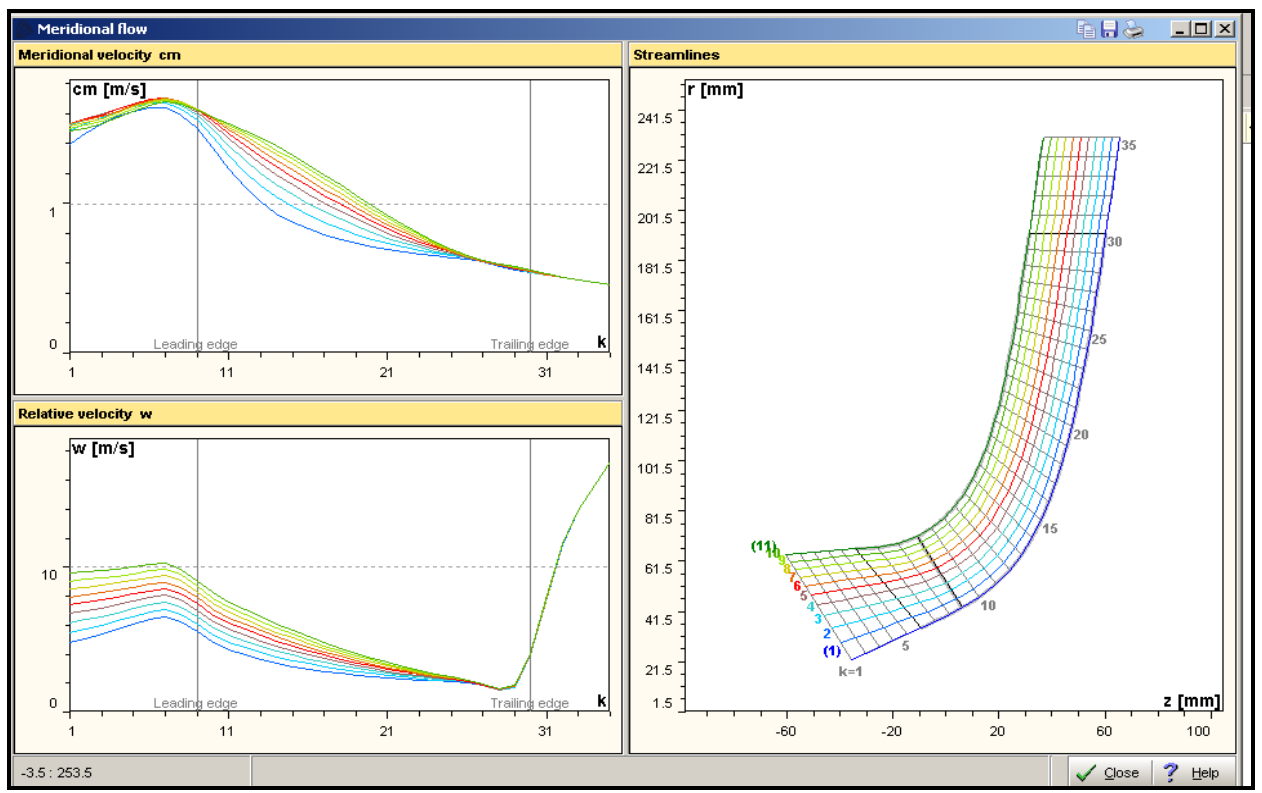

Gambar 7. Distribusi Kecepatan Meridional Menggunakan Software Setelah Optimasi

Kurva prestasi pompa yang dihasilkan oleh perangkat lunak setelah optimasi adalah sebagai berikut:

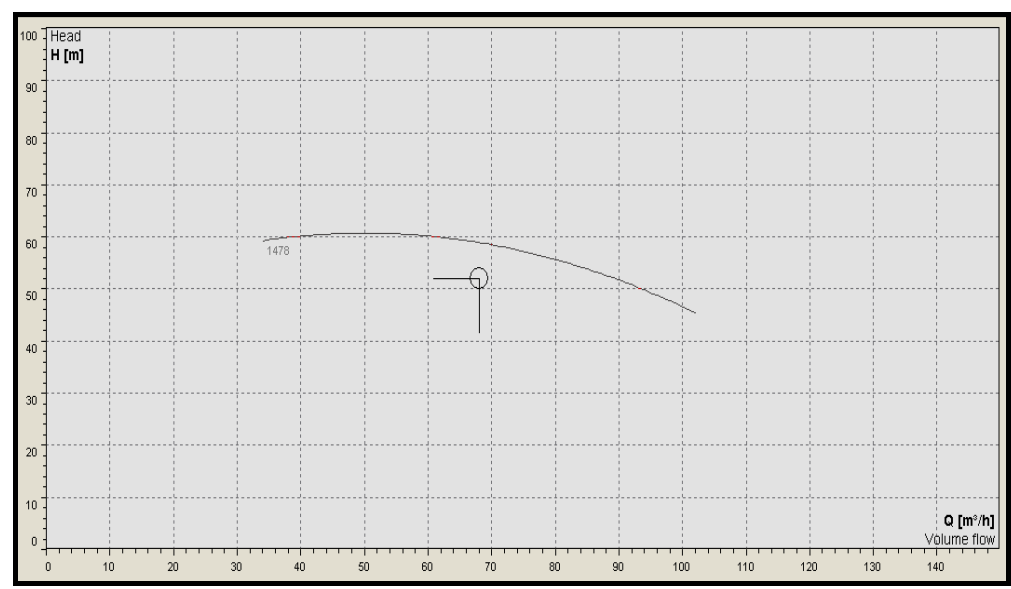

Gambar 8. Kapasitas (Q) vs Total Head (H) Hasil Optimasi 
Perhitungan menggunakan perangkat lunak CAE (Computer Aided Engineering) khusus impeler sehingga menghasilkan seperti pada tabel 1.

Tabel 1. Dimensi dan hasil perhitungan impeler pompa setelah optimasi

\begin{tabular}{clcc}
\hline No & \multicolumn{1}{c}{ Deskripsi } & Nilai & Satuan \\
\hline 1 & Kecepatan spesifik pompa (Ns) & 10,5 & $\mathrm{rpm}$ \\
2 & Daya Poros Pompa & 15,9 & $\mathrm{~kW}$ \\
3 & Diamater Poros Pompa & 70,0 & $\mathrm{~mm}$ \\
4 & Diameter Inlet & 133,0 & $\mathrm{~mm}$ \\
5 & Diameter Outlet & 384,0 & $\mathrm{~mm}$ \\
6 & Tebal sudu saat masuk t1 & 4,1 & $\mathrm{~mm}$ \\
7 & Tebal sudu saat keluar t2 & 4,563 & $\mathrm{~mm}$ \\
8 & Sudut masuk sudu $\beta 1$ & 17,4 & derajat \\
9 & Sudut keluar sudu $\beta 2$ & 18,3 & derajat \\
10 & Kecepatan masuk sudu U1 & 6,7 & $\mathrm{~m} / \mathrm{detik}$ \\
11 & Kecepatan keluar sudu U2 & 29,7 & $\mathrm{~m} / \mathrm{detik}$ \\
12 & NPSHR & 0,9 & $\mathrm{~m}$ \\
13 & Jumlah Sudu & 4,0 & buah \\
14 & Efisiensi Total & 61,0 & $\%$ \\
\hline
\end{tabular}

Hasil perhitungan menghasilkan gambar Distribusi tekanan pada impeler menggunakan perangkat lunak akan menghasilkan gambar 9 seperti berikut ini [7].

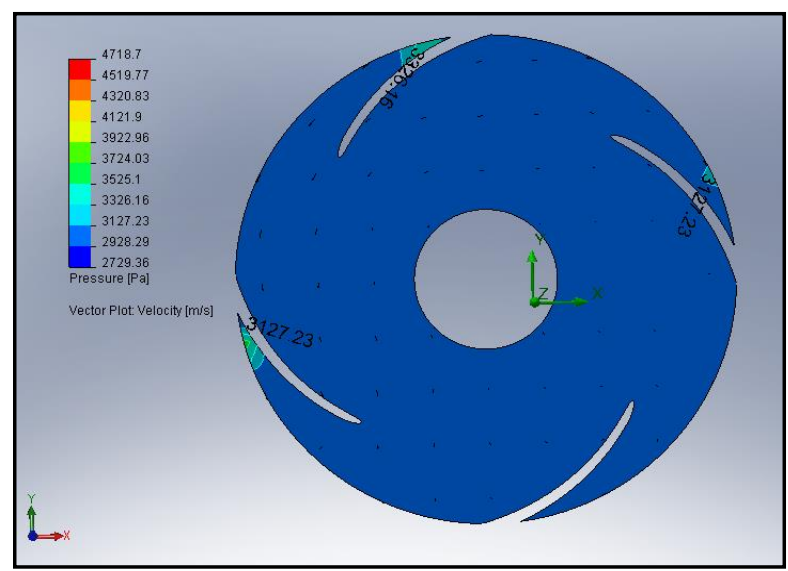

\section{Gambar 9. Distribusi Tekanan Menggunakan CAD-CFD SOLIDWORKS Tampak Depan}

Kemudian distribusi kecepatan menggunakan perangkat lunak akan menghasilkan seperti pada gambar 11.

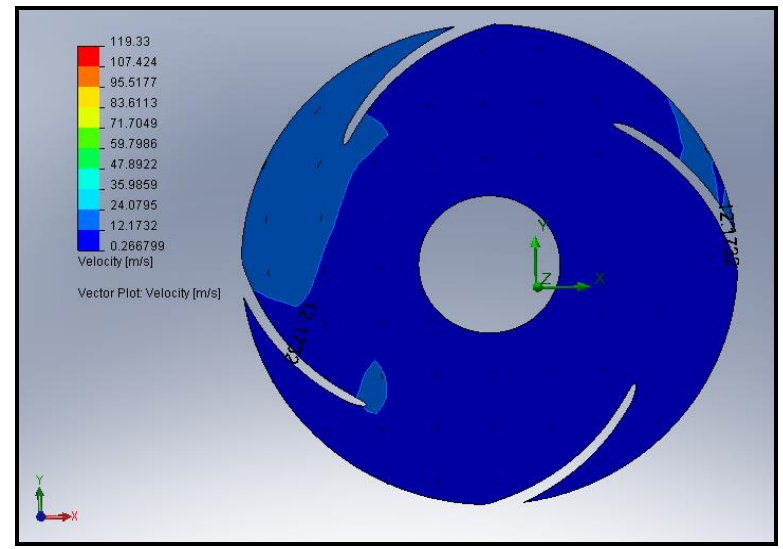

Gambar 10. Distribusi Kecepatan Menggunakan CAD-CFD COSMOS-FLOWORKS Tampak Depan 
Dalam simulasi dapat juga menentukan garis lintasan aliran kecepatan dengan perngkat lunak seperti pada gambar 11 dibawah.

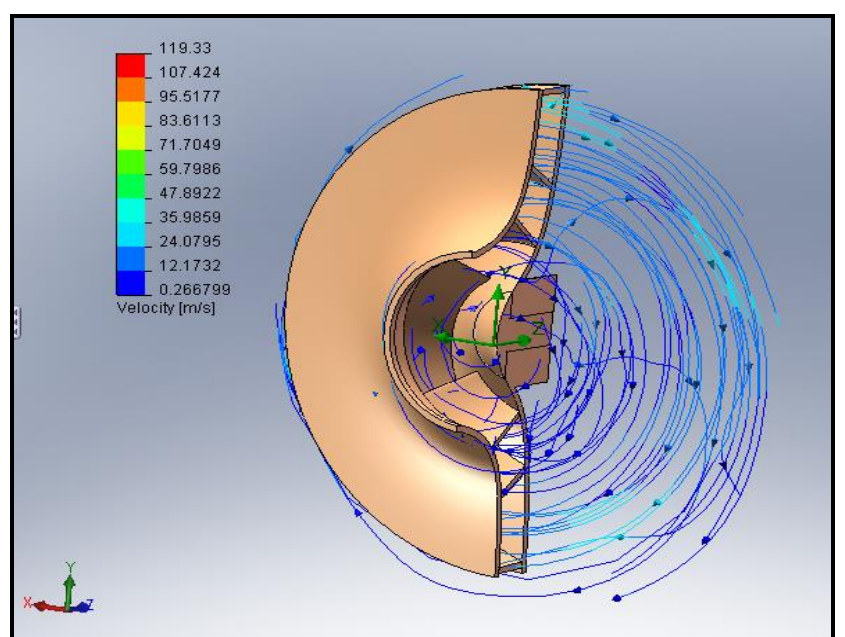

\section{Gambar 11. Garis Lintasan Kecepatan Menggunakan CAD-CFD COSMOS-FLOWORKS}

Sehingga dapat dibuat suatu perbandingan desain bentuk impeler sebelum dan sesudah optimasi, seperti pada gambar 12 .

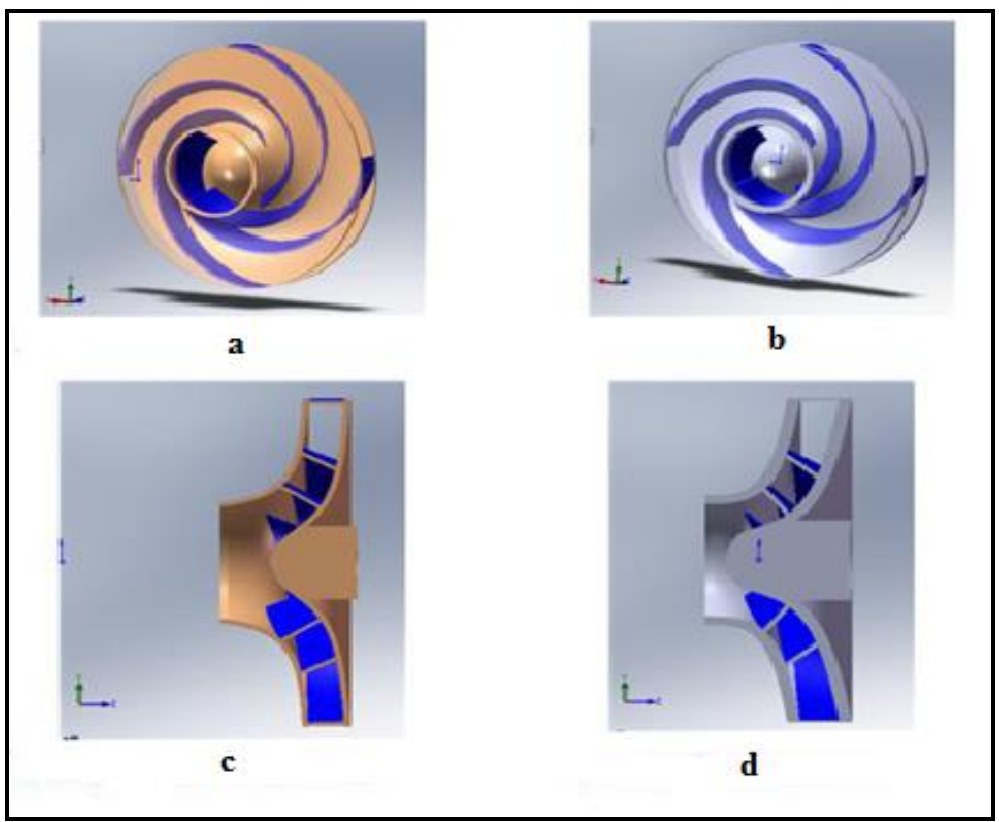

Gambar 12. Impeler 3D: a. Sebelum Optimasi Tampak Depan, b. Setelah Optimasi Tampak Depan, c. Sebelum Optimasi Tampak Samping, d. Setelah Optimasi Tampak Samping

\subsection{Manufaktur Impeler}

Adapun rekomendasi manufaktur / pembuatan impeler pompa dengan proses pengecoran metode gravitasi secara umum adalah seperti pada gambar 13 sebagai berikut: 


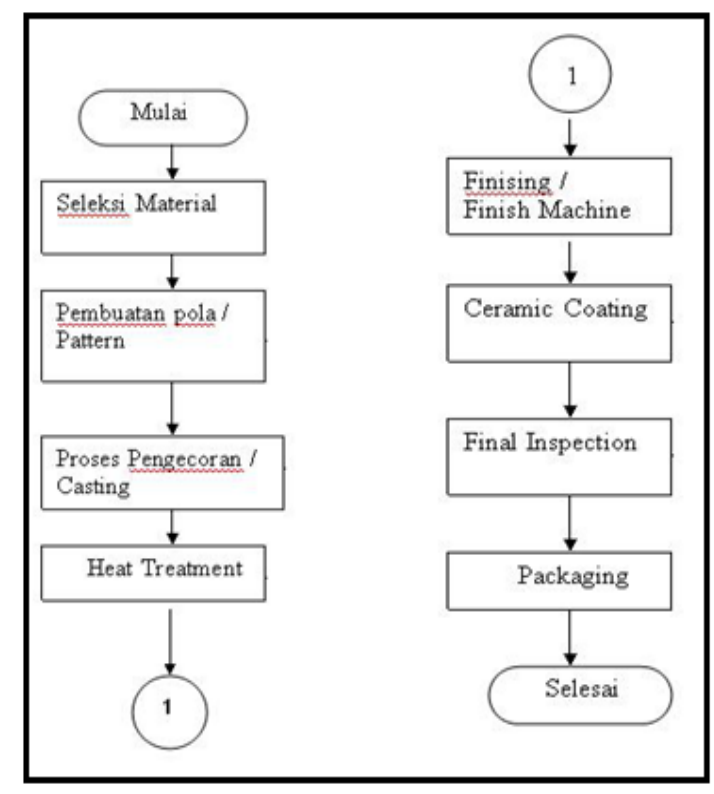

Gambar 13. Diagram Alur Pengecoran

\section{KESIMPULAN}

Setelah dilakukan penelitian pada profil impeler dengan menggunakan $C A D-C F D$, serta rekomendasi manufaktur impeler yang telah dioptimasi maka diperoleh:

1) Sudut masuk sudu impeler $\left(\beta_{1}\right)$ dan sudut keluar sudu impeler $\left(\beta_{2}\right)$ diusahakan diatas $10^{\circ}$, NPSHR 0,9 m untuk menyatakan sebagai angka aman terhadap kavitasi. Sudut incident $\mathrm{i}$ disarankan $0^{\circ}$ atau positif. Nss meningkat akan menurunkan NPSHR Pengubahan profil impeller akan menyebabkan beberapa parameter berubah. Efisiensi $\eta$ total dengan menggunakan Software meningkat dari pabrik $43 \%$ dengan putaran kerja $50 \mathrm{~Hz}$ menjadi $59 \%$. Setelah optimasi menjadi $61 \%$

2) Terlihat hasil perhitungan dengan menggunakan software sebelum optimasi mendekati sama dengan pengujian di lapangan uji. Adapun perbedaan karena rugi-rugi (loss) pada pengujian sesungguhnya / lapangan, baik itu adanya kebocoran, rugi-rugi belokan, pipa, katup, ataupun rugi aliran balik impeler keluar dari impeler masuk kembali ke sisi isap / side loses.

3) Kecepatan fluida sebelum masuk impeler tinggi kemudian menurun bervariasi pada daerah sudu LE/leading edge kemudian menyatu sebelum TE/ trailing edge lalu meningkat drastis keluar dari impeler dibantu dengan rumah/volute pompa sehingga kecepatan yang lebih tinggi dibandingkan sisi masuk impeler. Kecepatan relatif fluida air pada daerah LE shroud lebih tinggi dibanding dengan daerah hub dan kecepatan pada TE baik shroud maupun hub mempunyai kecepatan yang hampir sama.

4) Manufaktur impeler lebih menguntungkan dari segi biaya dan waktu pengadaan dibandingkan dengan membeli dari pabrikan.

Desain belum melibatkan ukuran rumah pompa/ casing sehingga hasil kurva yang dihitung belum sangat akurat.

\section{DAFTAR PUSTAKA}

[1] Anderson, John D, (1995), Computational Fluid Dynamics, New York: McGraw Hill.

[2] HK, Versteeg, (1995), An Introduction Computational Fluid Dynamics the finite volume method, London: Longman Scientific \& Technical.

[3] Firman Tuakia, (2008), Dasar-dasar menggunakan CFD Fluent, Bandung : Informatika-Bandung.

[4] API, (2003), Centrifugal pump for Petroleum, Petrochemical, and Natural Gas Industries, API Standard 610, 9th ed, Washington DC: API Publisher.

[5] Gould, (2000), Catalog and Manual Book GPM, Seneca Falls: Gould Pump.

[6] TCS, (2008), Final Inspection Report for Premier Oil WO 0460908, Bandung: TCS.

[7] Anonim, (2009), Solidwork Flow Simulation 2010 Tutorial, Massachusset: Dassault Systemes SolidWorks Corporation. 